\title{
O PERFIL E A POLÍTICA DE ATENDIMENTO AO ABUSADOR SEXUAL NO PRESÍDIO REGIONAL DE TIJUCAS (SC)
}

\section{The profile and the politics of attendance to the sexual abuser in the Regional Penitentiary of Tijucas (SC)}

\author{
Edgar Antonio Piva* \\ Aline R. Carvalho*
}

RESUMO

\begin{abstract}
A violência sexual contra crianças e adolescentes passou a ser abordada no Brasil na década de 90 , sendo incluída na luta pelos direitos humanos de crianças e adolescentes na Constituição Federal do Brasil de 1988, dando início a luta pela conquista de respeito e dignidade das crianças e adolescentes de todo o Brasil. A presente pesquisa foi realizada no Presídio Regional de Tijucas e no Fórum de Porto Belo, Santa Catarina, abrangendo o período de agosto de 1999, quando da fundação do Presídio, até março de 2007. Com esta pesquisa conseguimos conhecer o perfil dos detentos do Presídio Regional de Tijucas que cometeram crimes de natureza sexual contra crianças e adolescentes e avaliar as ações do Estado em face do agressor sexual, no sentido de prevenir o crime e orientar o seu retorno à convivência em sociedade. Esta pesquisa foi realizada com o intuito de contribuir para a reflexão do fenômeno, buscando oferecer subsídios para amparar possíveis programas junto aos abusadores sexuais encarcerados.
\end{abstract}

Palavras-chave: Violência Sexual; direitos humanos; abusadores sexuais; crianças e adolescentes.

\begin{abstract}
The sexual violence against children and adolescents started to be boarded in Brazil in the decade of 90 , and enclosed in the fight for the human rights of children and adolescents in the Federal Constitution of Brazil of 1988, giving to beginning the fight for the conquest of respect and dignity of the children and adolescents of all Brazil. The present research was carried through in the Regional Penitentiary of Tijucas and the Forrum de Porto Beautiful - Santa Catarina, having enclosed the period of August of 1999, when of the foundation of the Penitentiary, until March of 2007. With this research we obtain to know the profile of the prisoners of the Regional Penitentiary of Tijucas who had committed crimes of sexual nature against children and adolescents and to evaluate the actions of the State in face of the sexual aggressor, in the direction to prevent the crime and to instruct them in how to resume their lives in society. The research was carried through with intention to contribute for a reflection, being searched to offer subsidies to support possible programs together to the jailed sexual abusers.
\end{abstract}

Keywords: sexual violence; human rights; sexual abusers; children and teenagers.

\footnotetext{
Professor Mestre da Universidade do Vale do Itajaí (SC) e coordenador dos projetos de extensão Valorização da Vida e Ciranda. Endereço: Rua Pará, 315. Bairro Universitário, Tijucas, SC. Tel. (048) 3263 0576. E-mail: piva@univali.br

***adêmica do curso de Direito da Univali, campus Tijucas, SC.
} 


\section{RESUMEN}

La violencia sexual contra niños y adolescentes paso a ser abordada en el Brasil en la década de 90, siendo incluida en la lucha por los derechos humanos de niños y adolescentes en la Constitución Federal de Brasil de 1988, dando inicio a la lucha por la conquista de respeto y dignidad de los niños y adolescentes de todo el Brasil. La presente pesquisa fue realizada en el Presidio Regional de Tijucas y en el Juzgado de Porto Belo, Santa Catarina, abarcando el período de agosto de 1999, cuando da la fundación del Presidio, hasta marzo de 2007. Con esta pesquisa conseguimos conocer el perfil de los detenidos del Presidio Regional de Tijucas que cometieran crímenes de naturaleza sexual contra niños y adolescentes y evaluar las acciones del Estado en función del agresor sexual, no sentido de prevenir el crimen y orientar su retorno a la convivencia en sociedad. Esta pesquisa fue realizada con el intuito de contribuir para la reflexión del fenómeno, buscando ofrecer subsidios para amparar posibles programas junto a los abusadores sexuales encarcelados.

Palabras-Clave: Violencia sexual, derechos humanos, abusadores sexuales, niños y adolescentes.

O fenômeno da violência e exploração sexual de crianças e adolescentes passou a ser abordado, no Brasil, a partir da década de 90, sendo incluída na luta pelos direitos humanos de crianças e adolescentes preconizados na Constituição Federal do Brasil de 1988, no Estatuto da Criança e do Adolescente (lei 8.069/ 90) e na Convenção Internacional dos Direitos da Criança. Com vistas ao enfrentamento desta realidade, foi criado, na cidade de Chapecó, Santa Catarina, em maio de 1998, o Fórum Catarinense Pelo Fim da Violência e da Exploração Sexual Infanto-Juvenil. No ano de 2000, foi criado o Conselho Nacional dos Direitos da Criança e do Adolescente (CONANDA) que aprovou o Plano Nacional de Enfrentamento da Violência Sexual Infanto-Juvenil.

O Plano (2000) aponta que escolas e universidades podem ter um papel destacado no trabalho de pesquisa, orientação e prevenção da violência sexual contra crianças e adolescentes. O referido Plano (2000) está estruturado em seis eixos estratégicos: análise da situação, mobilização e articulação, defesa e responsabilização, atendimento, prevenção e protagonismo infanto-juvenil.
O objetivo deste artigo é apresentar os resultados de uma pesquisa realizada no Presídio Regional de Tijucas, Santa Catarina, sobre o perfil e o atendimento ao agressor sexual encarcerado. A pesquisa foi motivada a partir de nossas intervenções como extensionistas dos Projetos Valorização da Vida e Ciranda, da Univali, junto aos reeducandos do Presídio . As intervenções são realizadas semanalmente, durante uma hora e meia, no interior das galerias do presídio, nas quais são abordados temas como doenças sexualmente transmissíveis, drogas e violência sexual.

A pesquisa foi realizada no Presídio Regional de Tijucas, Santa Catarina, e no Fórum de Porto Belo, Santa Catarina, abrangendo o período de agosto de 1999, quando da fundação do Presídio, até março de 2007. A primeira parte da pesquisa foi de natureza quantitativa: consistiu na consulta dos arquivos do Presídio, do Fórum da Comarca de Tijucas e do Fórum de Porto Belo, identificando e analisando as informações e peças contidas nos Processos. Consultamos os dossiês, arquivos, relatórios, fichas e processos onde foram consignados registros sobre as ocorrências. Em seguida, realizamos a 
análise dos principais textos legais sobre a matéria da pesquisa em questão, especialmente o Código Penal Brasileiro, sobre o crime contra os costumes, e a Lei de Execução Penal (Lei 7.210/1984). Por fim, consideramos as observações e reações dos reeducandos quando da abordagem do assunto Violência Sexual contra crianças $e$ adolescentes nas intervenções educativas.

A pesquisa pretendeu responder as seguintes perguntas:

- Qual o perfil dos detentos do Presídio Regional de Tijucas que cometeram crimes de natureza sexual contra crianças e adolescentes?

- Quantos condenados após cumprimento da pena voltaram ao presídio por reincidência?

- Qual é a visão que o Estado tem do abusador sexual?

- Qual o atendimento e assistência que o Estado dá ao agressor sexual?

- Qual é a visão dos presos com relação aos abusadores sexuais?

O presente artigo está estruturado em duas partes. A primeira parte define os principais conceitos utilizados na pesquisa servindo de enquadramento teórico para a mesma, já a segunda parte apresenta e discute os dados pesquisados.

\section{Violência e exploração sexual}

O fenômeno da violência e exploração sexual de crianças e adolescentes é conseqüência da conjugação de vários fatores psicológicos, sócio-econômicos e culturais. Somente um modelo explicativo multicausal pode dar conta deste fenômeno. Daí a necessidade de uma abordagem multidisciplinar e multiprofissional do problema.

A violência sexual é apenas uma das formas de violência que atinge crianças e ado- lescentes. A violência contra crianças e adolescentes inclui 4 modalidades: a física, a psicológica, a sexual e a negligência. A violência sexual é uma das formas mais complexas, pois na maioria das vezes ela está associada a outras formas de violência e envolve a problemática do mundo da sexualidade humana.

A violência sexual é definida por Azevedo e Guerra $(2000,11)$ como "todo ato ou jogo sexual, relação hetero ou homossexual entre um ou mais adultos [...] e uma criança/ adolescente, tendo por finalidade estimular esta criança/adolescente ou utilizá-los para obter uma estimulação sexual sobre sua pessoa ou a de outra pessoa". É toda atividade de caráter sexual envolvendo menor de idade e um adulto ou adolescente mais velho, parente ou não, buscando unicamente o prazer do adulto ou adolescente mais velho envolvido, ainda que seja com aparente consentimento da vítima. A violência sexual é um fenômeno ao mesmo tempo intra-familiar, pois é provocada na maioria das vezes por membros da família caracterizada como incestuosa, e extrafamiliar, na medida em que é praticada por pessoas que não tenham laços de família com a vítima.

$\mathrm{Na}$ violência sexual intra-familiar, a relação do adulto com a criança é de consangüinidade, afinidade ou de mera responsabilidade, caracterizando-se como uma relação que denominamos de incestuosa. Estas relações sexuais podem se manifestar de diferentes formas desde carícias, manipulação da genitália, mama ou ânus, voyeurismo, exibicionismo, conversas ou telefonemas obscenas, até o ato sexual com ou sem penetração, com ou sem violência. Portanto, a violência sexual possui um espectro bastante amplo, indo das formas mais sutis e dissimuladas até as mais declaradas e violentas, deixando marcas profundas na vítima. Esta forma de violência é denominada por muitos pesquisadores do fenômeno como abuso sexual, distinguin- 
do-o de uma outra modalidade de violência que é exploração sexual. A exploração sexual se distingue do abuso sexual na medida em que envolve não apenas a satisfação sexual de um adulto ou adolescente mais velho, mas um uso comercial. A exploração sexual é a comercialização de atividades e expressões sexuais envolvendo crianças e adolescentes sob várias formas: prostituição infantil, produção e comercialização de materiais pornográficos envolvendo crianças por meio de fotos, revistas, vídeos, internet etc., shows eróticos, turismo sexual.

O Código Penal Brasileiro, nos artigos 213 a 234, define estas modalidades de violência sexual como crimes contra a liberdade sexual do cidadão: estupro (art. 213), atentado violento ao pudor (art. 214), sedução e corrupção de menores (art. 217 e 218), prostituição (art. 228), tráfico de mulheres (art. 231), ato obsceno (art. 233) e escrito ou objeto obsceno (art. 234).

\section{O abusador sexual}

As recentes pesquisas nos apresentam um perfil bastante heterogêneo do abusador sexual, incluindo desde pessoas tidas como "normais", pedófilos, psicopatas, mulheres e até adolescentes. Para a percepção do público em geral, os abusadores sexuais são pessoas desconhecidas, estranhas e perigosas, mas todas as pesquisas contrariam este senso comum. $\mathrm{Na}$ maioria dos casos, o agressor é uma pessoa que a criança conhece, confia e, freqüentemente, ama. Os estudiosos do fenômeno classificam os abusadores em dois tipos: o abusador circunstancial ou situacional e o abusador preferencial.

$\mathrm{O}$ agressor circunstancial é aquele indivíduo considerado "normal", acima de qual- quer suspeita, que em determinadas circunstâncias momentâneas pode cometer o abuso sexual. Geralmente são pais, padrastos, tios ou alguém ligado à família.

Já o agressor sexual preferencial é aquele indivíduo que prefere manter relações sexuais com crianças e/ou adolescentes. São conhecidos como pedófilos ou pederastas. Alguns pedófilos sentem atração sexual exclusivamente por crianças (tipo exclusivo), enquanto outros, às vezes, sentem atração por adultos (tipo não-exclusivo). Alguns preferem meninos, outras meninas.

A maioria dos abusadores sexuais são homens. A violência sexual é, na maioria das vezes, decorrência de um padrão de dominação $e$ de desigualdade de gênero entre homens e mulheres construído pela cultura, e não apenas decorrência de um distúrbio ou desequilibrio de personalidade. Estudos mais recentes mostram a existência de abusadores sexuais femininos. A violência sexual praticada por mulheres é um tema pouco estudado ainda e cercado de muitos tabus.

A maioria dos agressores sexuais não apresenta nenhum sinal de alienação mental, portanto, são juridicamente imputáveis. Deste grupo, aproximadamente $30 \%$ não apresenta nenhum transtorno psicopatológico da personalidade evidente e sua conduta sexual cotidiana e aparente parece adequada. Nos outros $70 \%$ estão as pessoas com evidentes transtornos da personalidade, com ou sem perturbações sexuais manifestas, tais como os psicopatas e sociopatas. Portanto, o abusador sexual deve ser criminalmente responsabilizado, porém, como todo condenado, deve ser objeto de atenção, cuidado e atendimento especializado, "objetivando prevenir o crime e orientar o retorno à convivência em sociedade" (art. 10 da Lei de Execução Penal, Lei no. 7.210). Todo agressor sexual deve passar por uma avaliação psicológica e ser acompanhado por uma equipe multiprofissional e interdisciplinar, tendo em vista a complexidade do problema. 
O perfil do abusador sexual no Presídio Regional de Tijucas

No decorrer da história e evolução da sociedade, o ser humano passou a ser sujeito de direitos e deveres. No Brasil, o primeiro Código Criminal foi feito apenas em 1830, oito anos após a independência, substituindo as arcaicas legislações do Reino. Ainda que o esforço fosse intenso por parte dos Magistrados, Promotores e Conselheiros tornou-se claramente visível que o Código Penal Brasileiro é insuficiente para abarcar os avanços da sociedade brasileira. Com estereótipos preconceituosos, o Código Penal Brasileiro, ainda define "mulher honesta" e "virgindade da mulher" persistindo nesta legislação moralista, desconsiderando todas as noções psicológicas que envolvem os possíveis traumas causados por um abuso sexual.

A partir da consulta inicial aos arquivos do Presídio Regional de Tijucas, no período de agosto de 1999 até março de 2007, constatamos que 67 (sessenta e sete) homens e 2 (duas) mulheres passaram pelo Presídio, acusados de se envolverem em crimes de natureza sexual. Porém, destes 69 casos nem todos se enquadram em crimes sexuais contra crianças $e$ adolescentes. Muitos eram crimes contra pessoas maiores de idade, o que não foi o objeto desta pesquisa.

A partir deste momento nosso material de pesquisa ficou reduzido, pois nem todos os processos dos 69 acusados encontravam-se no Presídio Regional de Tijucas, devido a transferência dos mesmos para outras Comarcas ou o término do cumprimento de suas penas. Por esse motivo tivemos que aprofundar nossa pesquisa em outros Fóruns, especialmente de Porto Belo, onde se encontravam arquivados muitos processos.
Conseguimos chegar ao fim desta pesquisa com o levantamento completo do perfil de 18 dos 69 agressores, todos acusados por crimes de ordem sexual contra crianças e adolescentes, abrangendo o Código Penal, dos artigos 213 ao 234 , com as mais diversas modalidades de crime contra a liberdade sexual.

Dos 18 agressores pesquisados, 9 eram solteiros, 6 casados ou conviviam em união estável e 3 divorciados. O que é possível verificar com esses dados é o numero de homens casados ou que conviviam em união estável que cometeram agressões de cunho sexual contra menores de idade. As vítimas eram suas próprias filhas, enteadas, sobrinhas, netas. Alegavam que as crianças os incitavam a cometerem tais atos, ou simplesmente culpavam suas companheiras pela monotonia de suas vidas e a ausência de relação sexual.

\begin{abstract}
A vitimologia ou a arte de culpar a vítima por comportamentos sedutores, provocativos, como manifestação de uma natureza feminina perversa e demoníaca, ou uma forma de inocentar o agressor através da sua patologização (SCHMICKLER, 2006, p. 29).
\end{abstract}

A média de idade dos agressores é de 23 a 48 anos de idade. O grau de escolaridade também é muito baixo: dos 18 casos, apenas um iniciou um curso superior sem chegar a completá-lo, os demais não ultrapassaram o ensino médio. Conforme Schmickler "a violência estrutural, de que grande parcela da população é vitima, é o pano de fundo de uma sociedade com profundas desigualdades" (SCHMICKLER, 2006, p. 31).

Em relação a origem $e$ naturalidade dos agressores, verificamos que 8 nasceram na Região da Costa Esmeralda e Vale do Rio 
Tijucas $^{2}, 5$ nasceram em outras cidades de Santa Catarina, e os outros 5 nasceram nos demais estados do Brasil, com predominância para os estados do Paraná e Rio Grande do Sul.

$O$ abuso sexual intra-familiar vem sendo discutido por diversos estudiosos e suas estatísticas são estarrecedoras. O fenômeno da criança e do adolescente agredido dentro do seu próprio lar é alarmante, pois o lar deixa de ser um lugar seguro para seus membros. Esta pesquisa reafirmou o que muitas crianças vêm passando dentro de suas próprias casas. Dos 18 acusados, 10 eram pais, padrastos e tios destas crianças e adolescentes, 5 eram amigos próximos da família da vítima, vizinhos ou conhecidos, e 3 eram desconhecidos tanto da família como da vítima. Segundo Ribeiro e Martins "embora os arranjos familiares tenham mudado com o transcorrer do tempo, a violência familiar continua marcando presença, caracterizada pela ação ou omissão do adulto sobre a criança e/ou adolescente" (RIBEIRO e MARTINS, 2006, p. 73).

Em relação às modalidades de crimes cometidos pelos abusadores pesquisados, usamos o Código Penal Brasileiro para classificálos. Dos 18 acusados por crimes sexuais, 6 são acusados pelo art.213 do Código Penal de Estupro, 10 acusados pelo art.214 do C.P. de Atentado Violento ao Pudor e 2 foram condenados pelo art.228. do C.P. por Favorecimento da Prostituição c/c art.229 do C.P.Casa de Prostituição. Com a lei 8.072, de 1990, o atentado violento ao pudor, assim como o estupro, passou a ser considerado crime hediondo. Atualmente, o atentado violento ao pudor é o crime correspondente ao estupro, quando praticado contra meninos. A recomendação do relatório final da CPMI da Exploração Sexual, de 2004, é unifi- car os dois tipos de crime e ampliar a pena quando praticado contra pessoas vulneráveis, entre essas, se incluem crianças e adolescentes.

A política de atendimento do Estado ao abusador sexual do Presídio Regional de Tijucas

A Lei 7.210/1984, do art.10 da Lei de Execução Penal prevê que: a assistência ao preso e ao internado é dever do Estado, objetivando prevenir o crime e orientar o retorno à convivência em sociedade. Durante nossa pesquisa no Presídio, pudemos verificar, por meio de registro e entrevistas, que jamais o Estado disponibilizou qualquer tipo de assistência ao Abusador Sexual. O único fato que podemos relatar é de um acusado pelo crime de estupro, que pagou para receber a assistência de uma psicóloga.

O objetivo da assistência, como está expresso, é prevenir o crime e orientar o retorno à convivência em sociedade, porém, ficou evidente que os objetivos referidos, ficam apenas na frieza do papel, que tudo aceita. Então como encarar a possibilidade de um sujeito acusado por crimes tão bárbaros, voltar à convivência da sociedade, sem passar por nenhum tipo de tratamento psicológico ou patológico? Infelizmente a lei não cumpre o seu destino, ficando esquecida nas gavetas das instituições brasileiras.

Dos 18 acusados por crimes sexuais contra crianças e adolescentes, nenhum destes retornou ao presídio de Tijucas por reincidên-

\footnotetext{
2 As regiões Costa Esmeralda e Vale do Rio Tijucas são compostas pelos seguintes municípios do litoral catarinense: Itapema, Porto Belo, Bombinhas, Tijucas, Canelinha, São João Batista, Major Gercino e Nova Trento.
} 
cia. Porém, este dado positivo não é resultado de uma política pública do Estado.

O Estado tem a obrigação de garantir as necessidades básicas do ser humano, garantias que a própria Constituição Federal do Brasil de 1988 assegura. Como prevê a Lei de Execuções Penais, o Estado deve garantir ao indivíduo ajuda emocional, educacional, tratamento psicológico e auxílio jurídico. Do contrário, o condenado cumpre sua pena e retorna à sociedade do mesmo jeito ou pior do que antes: volta a abusar sexualmente de crianças e adolescentes. O Presídio Regional de Tijucas é uma exceção: preocupa-se com a reeducação dos presos promovendo projetos de educação e de profissionalização dos mesmos, sendo considerado no estado um presídio modelo.

Ao questionarmos os presos sobre qual a pena justa para um homem que comete o crime de abuso sexual, a resposta foi de total indignação. Muitos deles esbravejaram e disseram que "a solução para estes presos era a pena de morte, cadeira elétrica, prisão perpetua". Outros até cogitaram que "deveriam estes receber como tratamento o mesmo que fizeram". Quando perguntamos se acreditavam que estes poderiam ser pessoas doentes, afirmaram que "não era doença coisa nenhuma e sim coisa de gente sem vergonha".

A discriminação que um condenado por abuso sexual recebe de seus companheiros de cela, bem como dos demais presos, é muito grande. Foi visível que estes são repudiados pelos demais, e logo ao entrarem no presídio, recebem o apelido de "DUC". Ouvimos dos presos relatos de tortura e até de estupro. Abaixo mencionamos o relato de um preso que nos contou como é tratado o preso recém chegado ao Presídio Regional de Tijucas, acusado por abuso sexual:

\begin{abstract}
A.L. 26 anos -- Quando um estuprador chega aqui no Presídio, todo mundo grita de sela em sela, DUC, DUC, DUC, para todos da cadeia saberem que chegou, um art. 213, aí a bagunça toma conta, e todo mundo fica na agonia de encontrar ele, pra mostrar pra ele como é bom estuprar menininha.
\end{abstract}

A opinião da sociedade não difere muito da opinião dos presos, a não ser pela sutileza das palavras que as pessoas usam para se referirem aos abusadores. Das 30 pessoas questionadas, 23 foram favoráveis à pena de morte, 5 acreditam em uma possível recuperação e reinserção na vida social, e 2 pessoas acreditam que são eles pessoas doentes que precisam de ajuda psiquiátrica.

Por meio da pesquisa foi possível conhecer o perfil dos detentos do Presídio Regional de Tijucas que cometeram crimes de natureza sexual contra crianças e adolescentes $e$ avaliar as ações do Estado em face ao agressor sexual, no sentido de prevenir o crime e orientar o seu retorno à convivência em sociedade. Constatamos claramente a falta de interesse do Estado para com essas pessoas, a ausência de políticas de Estado para minimizar estes problemas. Por outro lado, pudemos presenciar inúmeras iniciativas da comunidade (indivíduos, grupos e entidades empresariais e educacionais), em parceria com a Direção e o Conselho Comunitário do Presido, no sentido de proporcionar aos presos um atendimento educacional, profissional, religioso, psicológico e jurídico. Porém, a superpopulação carcerária tem dificultado a realização e a continuidade destas iniciativas. 


\section{REFERÊNCIAS}

AZEVEDO, M.A. \& GUERRA, V. N. A. Infância e violência doméstica: fronteiras do conhecimento. 3. ed. São Paulo: Cortez, 2000.

FORUM CATARINENSE PELO FIM DA VIOLÊNCIA EDA EXPLORAÇÃO SEXUAL INFANTO-JUVENIL, Informativo, Florianópolis, agosto, 2004.

FURNISS, T. Abuso Sexual da Criança. 2. ed. Porto Alegre: Artmed, 2002.

GABEL, M. Crianças vítimas de abuso sexual. 1. ed. São Paulo: Summus, 1997.

AZAMBUJA, M. R. F. Violência sexual intrafamiliar: É possível proteger a criança? 1. ed. Porto Alegre: Livraria do Advogado, 2004.

BRASIL. Código Penal. 4. ed. São Paulo: Rideel, 2006.

RIBEIRO, M. M. \& MARTINS, R. B. Violência doméstica contra a criança e o adolescente. $1^{\circ}$ ed. Curitiba: Afiliada, 2004.

ASSOCIAÇÃO BRASILEIRA MULTIPROFISSIONAL DE PROTEÇÃO À INFÂNCIA E ADOLESCÊNCIA. Abuso sexual: mitos e realidade. Petrópolis: Autores \& Agentes \& Associados, 1997.

AZEVEDO, M. A. \& GUERRA, V. N. A. (Org.). Crianças vitimizadas: a síndrome do pequeno poder. São Paulo: Iglu, 1989.
CARVALHO, A. R. \& PIVA, E. A. Violência Sexual Contra Criança e Adolescente. Tijucas: 2006. Trabalho não publicado.

CENTRO BRASILEIRO PARA A INFÂNCIA E ADOLESCÊNCIA. Estatuto da Criança e do Adolescente. Brasília: Ministério do Bem-Estar Social, 1993.

DAMASIO, E. J. Código Penal Anotado. São Paulo: Saraiva, 1995.

FORUM CATARINENSE PELO FIM DA VIOLÊNCIA E DA EXPLORAÇÃO SEXUAL INFANTO-JUVENIL, Informativo, Florianópolis, agosto, 2004.

SCHMICKLER, C. M. A revelação do indizível. Um estudo sobre o protagonista do abuso sexual incestuoso contra crianças e adolescentes. (Tese de Doutorado) São Paulo: PUC, 2001.

VERONESE, J. R. P. Crianças e adolescentes vítimas: violência gerada por quem? In: Revista Roteiro. Joaçaba, v.18, n.35, p.159-175, jan./jun. 1998.

SCHMICKLER, C. M. O protagonista do abuso Sexual. Sua lógica e estratégias. Chapecó: Argos, 2006.

Plano nacional de enfrentamento da violência sexual infanto-juvenil. Natal; Ministério da Justiça/Secretaria de Estado dos Direitos/Departamento da Criança e do Adolescente, CEDECA/BA - Secretaria Executiva do ECPAT, Casa Renascer, CECRIA, Fórum DCA: 2000.

Texto recebido em 21 fev. 2008. Texto aprovado em 17 mar. 2008. 